\title{
Implementing Vertical Integration in the Industry 4.0 Journey: Which Factors Influence the Process of Information Systems Adoption?
}

\author{
Verônica Maurer Tabim ${ }^{1}$ - Néstor Fabián Ayala ${ }^{1}$ - Alejandro G. Frank ${ }^{1}[$ \\ Accepted: 31 October 2021 \\ (C) The Author(s), under exclusive licence to Springer Science+Business Media, LLC, part of Springer Nature 2021
}

\begin{abstract}
One of the key principles of Industry 4.0 is the implementation of vertical integration, which considers the integration of information systems from different hierarchical levels in a company to support decision-making with real-time data flows. Companies face challenges when they want to implement vertical integration, which is not trivial due to the risks inherent to the decision stages of adoption. We investigate the main factors influencing the different stages of adoption of vertical integration to provide a clearer view of what managers should consider at each stage. We adopt a multi-case study approach based on the investigation of ten companies that followed this adoption process. We develop a framework with 22 factors deployed in the three stages of decision (knowledge, persuasion, and final decision) and three main dimensions of analysis: technology, organization, and environment. We analyze the potential tensions between these factors and show how managers should balance such factors during the decision stages.
\end{abstract}

Keywords Industry $4.0 \cdot$ Vertical integration $\cdot$ Information systems $\cdot$ Smart Manufacturing $\cdot$ Technology adoption

\section{Introduction}

After ten years of research, Industry 4.0 has been consolidated as a technology evolution model which integrates several emerging technologies grounded on the Industrial Internet of Things (IoT) to create cyber-physical systems (Khan \& Javaid, 2021; Li, 2018; Lu, 2017; Meindl et al., 2021). One of the core concepts of Industry 4.0 is Smart Manufacturing, which is concerned with the way production activities are executed with the support of sensors, computing platforms, communication technology, data-intensive modeling with artificial intelligence (AI), automated control, simulation, and other advanced IoT-based tools, to create transparent, predictive and adaptable manufacturing systems (Dalenogare et al., 2018; Frank et al., 2019; Kusiak, 2018; Liu \& Xie, 2020; Peruzzini et al., 2017; Uysal \& Mergen, 2021). One of the key principles of Industry 4.0 in the Smart

Alejandro G. Frank ag.frank@ufrgs.br

1 Organizational Engineering Group (Núcleo de Engenharia Organizacional - NEO), Department of Industrial

Engineering, Universidade Federal do Rio Grande do Sul, Porto Alegre, Brazil
Manufacturing domain is the implementation of vertical integration, i.e., the integration of information systems from different hierarchical levels in the company - from the factory floor to the middle and upper management levels - to provide real-time data flow and support decision-making (Peruzzini \& Stjepandić, 2017a; Wang et al., 2016). Vertical integration enables smart machines to form a self-organized system that can be dynamically reconfigured to adapt to different products. Besides, massive information is collected and processed to make the production process transparent, increasing production reliability and factory flexibility (Branger \& Pang, 2015; Pérez-Lara et al., 2018; Schuh et al., 2020a; Wang et al., 2016). With such integration, companies obtain a transparent, predictive, and adaptable smart manufacturing system, being vertical integration, therefore, considered the first step toward factory-level Industry 4.0 (Schuh et al., 2020a).

However, to implement vertical integration, companies are facing the challenge of integrating several information systems. As stated by Schuh et al. (2020a), before Industry 4.0, Information Technologies (ITs) (e.g., ERP, PLM) and Operational Technologies (OTs) (e.g., MES, SCADA, PLCs) sought to achieve their goals independently. This previous stand-alone approach formed closed systems and different communication protocols, creating complex technical 
obstacles for systems and architectures to achieve a smooth data flow between systems (Peruzzini \& Stjepandić, 2017b). Additionally, each of these systems usually has different providers, database structures, and nomenclatures, making their integration challenging (Pereira et al., 2020). Thus, adopting and integrating information systems to achieve an Industry 4.0 level of vertical integration is not trivial, as it involves risky and uncertain decisions (Junior et al., 2019). According to Janssen et al. (2020), the constant evolution of systems, combined with increased complexity, high costs, and variety, hinders companies' success in adopting vertical integration. However, although considered crucial for Industry 4.0, vertical integration remains little explored by information and technology management scholars. Most of the literature refers only to interactions between systems or mentions vertical integration as a general concept together with other Industry 4.0 technologies (Bellini et al., 2021; Fernandez-Viagas \& Framinan, 2021; Ismail \& Kastner, 2016; Pérez-Lara et al., 2018; Tamas et al., 2019; Wang et al., 2016; Xu et al., 2018). Although such studies have been important to elucidate the strategic and operational role of vertical integration, there is a lack of analysis on the factors (i.e., details and complexities) of adopting this system in the organizational context. Therefore, further research is necessary to identify the factors that affect the adoption of information systems for vertical integration in manufacturing companies pursuing an Industry 4.0 level. Thus, we approach this problem through the following research question: What factors influence the adoption of information systems for vertical integration in the context of Industry 4.0, and how do they influence such adoption?

Two main aspects must be considered to answer the above questions: the technology adoption process and the technological, organizational and environmental aspects that influence their utilization. First, we use the theory of diffusion of innovation (DOI) by following the innovation-decision process model (Rogers, 2003) to study information systems adoption for vertical integration. We considered the knowledge, persuasion, and decision stages of this process. This theory is mainly based on the characteristics of the technology and users' perceptions of innovation. Secondly, since the adoption of information systems depends not only on factors directly related to them but also on organizational and environmental aspects (Junior et al., 2019), we employ the technology-organization-environment structure (TOE) (Tornatzky \& Fleischer, 1990) as a basis for the identification of different sociotechnical factors in the adoption of systems for vertical integration. We investigate these main factors influencing the different stages of adoption of vertical integration to provide a clearer view of what managers should consider at each stage. We adopt a multi-case study approach based on the investigation of ten companies that followed a vertical integration implementation process. We develop a framework with 22 factors deployed in the three stages of decision (knowledge, persuasion, and final decision) and three main dimensions of analysis: technology, organization, and environment. We analyze the potential tensions between these factors and show how managers should balance such factors during the decision stages. As the main contribution for theory, our results show how factors related to vertical integration change alongside the different decision stages of the technology adoption process. While the literature has considered general factors for information system integration, we contribute with the particularities of the Industry 4.0 context, emphasizing the integration between information and automation technologies necessary for vertical integration. We show that sociotechnical factors and tensions between them are present and need to be managed to overcome each of the adoption process stages. On the other hand, managers can learn the specific requirements they will need to implement vertical integration. We discuss infrastructure and organizational needs and how they need to manage the potential tensions among the different requirements. In doing so, we propose a structure to guide professionals on their path towards vertical integration, considering the particularities of an Industry 4.0 context.

The remainder of this article is organized as follows. Section 2 reviews the literature on Industry 4.0 and vertical integration and the two theoretical lenses used. Section 3 details the research methodology used and the case studies, data collection, and analysis. Section 4 presents the results, Section 5 discusses the results, while Section 6 highlights the limitations of this study and future research directions.

\section{Theoretical Background}

\subsection{Industry 4.0 and Vertical Integration}

The Industry 4.0 concept has been summarized by Frank et al. (2019) as the development and integration of four smart dimensions - smart manufacturing, smart supply chain, smart product service-systems, and smart working - supported by four base technologies, namely the Internet of Things (IoT), cloud computing, big data, and data analytics, including the use of artificial intelligence (AI), which can have several applications in these dimensions, accomplished by the use of advanced technologies such as robotics and additive manufacturing. In this paper, we focus only on Smart Manufacturing, which is the central concept of Industry 4.0 considering the internal industrial activities of companies (Haleem \& Javaid, 2019; Iaksch et al., 2021; Meindl et al., 2021). Along with all technologies involved, Industry 4.0 is formed by three key principles: horizontal integration, vertical integration, and end-to-end engineering (Kagermann, 2013). Horizontal integration refers to the 
Table 1 Main information systems that can compose vertical integration

\begin{tabular}{|c|c|c|}
\hline Levels & Pyramid components & Role \\
\hline Level 0 and 1 & Instrumentation & $\begin{array}{l}\text { Source of the data derived from a measurement of the process. The } \\
\text { instrumentation measures a specific process variable and can distribute } \\
\text { this information to a PLC. The data generated is used only to monitor } \\
\text { process variables (raw data). }\end{array}$ \\
\hline Level 2 & Supervisory Control and Data Acquisition (SCADA) & $\begin{array}{l}\text { System used for data acquisition or process control. Thus, the processes } \\
\text { communicate with several devices in real-time. In this context, devices } \\
\text { called PLC (Programmable Logic Controller) are generally used. } \\
\text { SCADA takes raw data from the PLC and transforms it for use only in } \\
\text { the production process (allows limited access to the history of informa- } \\
\text { tion). }\end{array}$ \\
\hline Level 3 & Manufacturing Execution System (MES) & $\begin{array}{l}\text { A system with functions focused on the execution of production activities. } \\
\text { MES establishes a direct link between planning and the shop floor. It } \\
\text { generates accurate and real-time information that promotes the opti- } \\
\text { mization of all production stages, from the issuance of an order to the } \\
\text { shipment of finished products. The MES has data processed for decision- } \\
\text { making (allows access to the history of this information). }\end{array}$ \\
\hline \multirow[t]{2}{*}{ Level 4} & Enterprise Resource Planning (ERP) & $\begin{array}{l}\text { An information system with a unified view of the business, covering all } \\
\text { departments and their corresponding functions. It covers product design, } \\
\text { operations, logistics, sales and marketing, information storage, material } \\
\text { planning, human resources, finance, and project management. }\end{array}$ \\
\hline & Product Lifecycle Management (PLM) & $\begin{array}{l}\text { Business software manages all data associated with a product during its } \\
\text { life cycle phases, including design, manufacture, use, maintenance, } \\
\text { recycling, and disposal. It is often referred to as a "single registration } \\
\text { system" for product data throughout the product's life cycle. }\end{array}$ \\
\hline
\end{tabular}

integration of different systems to enable communication between all stages in the supply chain. This includes the connection between logistics, production, and design, within and across different companies. Vertical integration, in turn, refers to the integration of systems at different hierarchical levels in an organization, from production to management (Dalenogare et al., 2018). Finally, end-to-end engineering refers to the integration of engineering throughout the value chain, from its development to after-sales (Kagermann, 2013). In this study, we focus on vertical integration, building on previous studies showing it to be an initial and essential step for the implementation of Industry 4.0 internally, at the factory level (Frank et al., 2019; Schlechtendahl et al., 2014; Schuh et al., 2020a; Wang et al., 2016).

The vertical integration of manufacturing companies is widely represented by the ISA-95 standard pyramid model (Tamas et al., 2019). This model specifies the limits and types of data exchange for each level between the systems (ISA, 2020), as described in Table 1: (a) level zero represents the physical production process; (b) level one presents the sensors and other actuators; (c) level two reports the functions of supervision (SCADA), monitoring and control of production processes (PLC); (d) level three presents the manufacturing management layer (MES); (e) level four presents the business management layer (ERP/PLM). As explained in this model, to achieve vertical integration, the first step is to digitalize physical objects on the shop floor with sensors, actuators, and programmable logic controllers
(PLC) (Jeschke et al., 2017). Data is then collected with SCADA systems for production control. At the operational layer, the MES obtains data from SCADA to control and optimize manufacturing workflows and provide information about production status to the ERP system at the corporate layer (Frank et al., 2019; Ismail \& Kastner, 2016; Wang et al., 2016). Additionally, some firms employ PLM systems at the corporate layer to control product registration at all stages of the development process (Antonio et al., 2017; Pérez-Lara et al., 2018). According to the Industry 4.0 maturity index model from the German National Academy of Science and Engineering (ACATECH), which provides companies with guidelines for implementing Industry 4.0, the path towards Industry 4.0 starts with visibility and transparency, which is precisely the goal achieved by implementing vertical integration (Schuh et al., 2020a).

In a typical firm, each of the described systems has its technical particularities (e.g., database and communication protocol), brand, and length of implementation. Before the advent of Industry 4.0, each of these systems was usually acquired and implemented by the companies without regard to the following integration. Consequently, companies currently face a tangle of systems (legacy or not), and the complexity of different software architectures makes the path towards Industry 4.0 more difficult. Therefore, adopting information systems for vertical integration is a challenge that requires a robust model of technology adoption suitable for the context of Industry 4.0. Moreover, due to the 
innovative characteristics and complexity of the concepts associated with vertical integration, manufacturing companies struggle to define how to select the information systems necessary to achieve this level of integration (Ghobakhloo $\&$ Ching, 2019). To exemplify this challenge, Schuh et al. (2020b) evaluated 70 manufacturing companies in Europe striving to enter Industry 4.0 and showed that only $4 \%$ of those companies achieved data and information visibility through vertical integration. Another series of studies conducted in Brazil showed that most companies engaged in Industry 4.0 initiatives are still concerned with vertical integration as a priority focus of investment (CNI, 2016; Dalenogare et al., 2018). Several other reports from consulting companies around the world have reported the priority given by companies to vertical integration, even though ten years have gone by since the Industry 4.0 concept was launched (e.g., McKinsey \& Company, The Boston Consulting Group, and IBM Institute for Business Value) (Brunelli et al., 2017; Liggesmeyer, 2014; Snyder et al., 2020). As explained in the following section, we propose that such a struggle to implement vertical integration can be addressed from the innovation diffusion perspective.

\subsection{A Framework to Study the Adoption of Vertical Integration: Using the Innovation Diffusion Perspective and Technology-Organization-Environment}

While the adoption of innovative technologies is influenced by several factors (Alshamaila et al., 2013; Maduku et al., 2016; Oliveira et al., 2019), the Diffusion of Innovation (DOI) theory, through its innovation-decision process model (Rogers, 2003), allows structuring the analysis of the adoption of vertical integration. The innovation-decision process model comprises five stages: knowledge, persuasion, decision, implementation, and confirmation. The first three stages refer to evaluating the adoption decision, and the last two refer to post-implementation analysis. We focus our study on the first three stages that cover the assessment of whether to adopt or reject an innovation. Before making a decision (adoption or rejection), managers need to gain an understanding of how the innovative technology works (knowledge) and then take a favorable or unfavorable attitude towards it (persuasion).

Nevertheless, due to the broad impacts on organizations of information systems adoption for vertical integration, our research problem requires a more comprehensive view of how adoption should be handled, considering multiple contexts. In this context, the innovation-decision process model shows to be limited since it does not comprise aspects beyond the technology itself. Thus, to have a complete overview on the adoption of vertical integration, we combine this model with the Technology-Organization-Environment (TOE) framework (Tornatzky \& Fleischer, 1990) to achieve a perspective that contemplates changes in the organizational structure, as well as in its communication with the external environment (Schuh et al., 2020a). The TOE framework explains that the decision to adopt an innovation, as the development of a new information system, is influenced by factors in three contexts: technology, organization, and environment (Tornatzky \& Fleischer, 1990). The technological context includes the internal and external technologies present in an organization's business ecosystem. The organizational context refers to its internal characteristics and resources, including its size, degree of centralization, degree of formalization, management structure, hierarchy, and procedures. Finally, the environmental context is related to the industry, competitors, and the company's relationship with other institutions, including the government.

Thus, the TOE framework allows us to understand the broader scenario in which innovation occurs by integrating the different factors that influence the adoption of technologies (Oliveira et al., 2019). It is among the most commonly employed structures in research on the adoption of technological innovations (Maduku et al., 2016; Yeo \& Grant, 2018), including the adoption of information systems (Thong, 1999), IT (Bose \& Luo, 2011), RFID (Wei et al., 2015), cloud computing (El-Haddadeh, 2020; Senyo et al., 2016), Enterprise Resource Planning (ERP) (Junior et al., 2019) and Industrial Augmented Reality (IAR) (Masood \& Egger, 2020). Although some studies have used the TOE framework to analyze information systems and ERP adoption, our research brings a new perspective. It aims to investigate the vertical integration of these systems. Prior research on Industry 4.0 has acknowledged the importance of considering sociotechnical factors when Industry 4.0-related technologies are implemented (Marcon et al., 2021). By considering this broader perspective, more factors can be identified that influence the adoption of an information system in the new scenario of Industry 4.0. Thus, as presented in Fig. 1, the conceptual framework guiding our research combines the innovation-decision process model of the Diffusion of Innovation Theory (DOI) (Rogers et al., 2019) with the Technology-Organization-Environment (TOE) framework (Tornatzky \& Fleischer, 1990). This conceptual framework allows us to identify the main factors of each TOE dimension influencing the adoption of information systems for vertical integration across the three innovation-decision process stages. Because these factors may change along the stages, we aim to understand which should be considered in each specific stage of decision. 
Fig. 1 Conceptual framework for the innovation-decision process of adoption of IT systems aiming at vertical integration

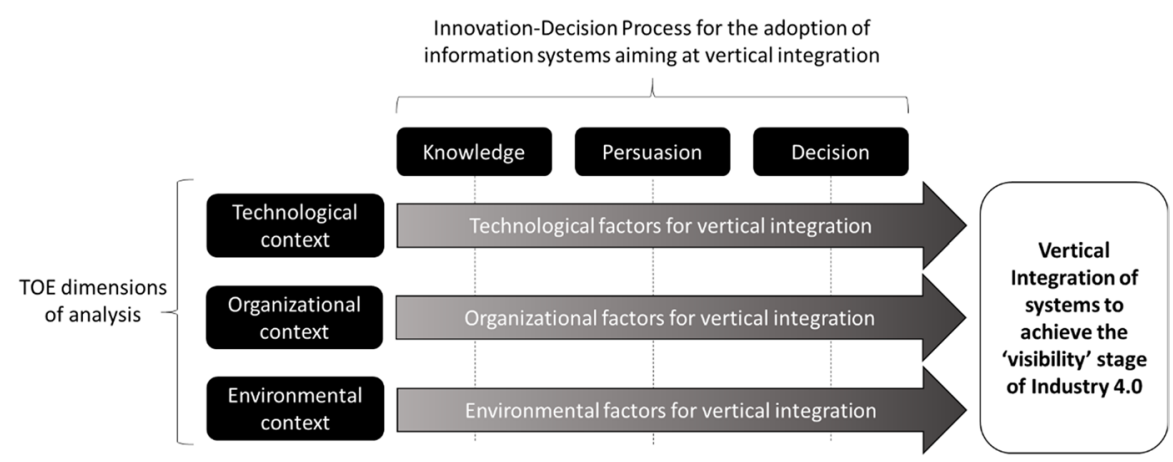

\section{Research Method}

Our study adopts a qualitative approach through a multiple case study to understand the factors that influence the adoption of information systems for vertical integration in manufacturing companies pursuing an Industry 4.0 level. The decision for the qualitative analysis of case studies derives from the recommendations of Voss et al. (2002). They suggest using this approach when the goal is to explore a new phenomenon and build theories based on an in-depth analysis of the field. This approach is based on data collection with several representatives of the studied environment who provide insights and understand the context of the problem (Ayala et al., 2017). Therefore, we conducted an exploratory study grounded on a conceptual literature-based framework (Fig. 1) and semi-structured interviews (see Appendix 1) with ten manufacturing companies based in Brazil.

\subsection{Case Study Selection}

The cases were selected using theoretical sampling; that is, they were selected because they were particularly suitable to shed light on the constructs (Eisenhardt \& Graebner, 2007). We intentionally chose companies from different industry segments to produce contrasting results that can offer a broader overview of the phenomenon and facilitate the generalization of results. Following this criterion, we contacted representatives of the Brazilian Chamber of Industry 4.0 and the Southern Brazil Federation of Industries to identify outstanding companies of this country in technology implementation (i.e., high technology intensity) and are currently engaged in digital transformation and Industry 4.0 programs. The associations map these types of initiatives in the country, thus providing a reliable list of potential case studies for our investigation. We obtained a list of 60 potential companies for investigation, contacted them by e-mail, and then made phone calls and video calls to discuss further their interest in participating in this research. From this initial group of companies, we refined our selection only to companies implementing or having already implemented vertical integration to advance in the Industry 4.0 maturity journey. Some companies were not eligible because they were focused on other types of technology implementation, such as intensive use of robotics or artificial intelligence for specific purposes like smart maintenance, which fell out of the scope of this study. Besides, some other companies were considered ineligible because they only implemented specific IT, such as SCADA or MES, but without vertical integration. Thus, we obtained a final list of ten companies that were considered the most suitable to understand the whole decision-making process for implementing vertical integration concepts.

Table 2 provides a brief description of the selected cases. The names of companies and respondents were hidden to preserve anonymity, and we adopted codenames to represent them. Amongst these case studies, ClothingCo, ChemicalCo, TerminalsCo, VehicleCo, PowertoolsCo, ElectronicCo, and AgricultureCo2 reported their process of adopting an MES system aiming at vertical integration with their extant systems. AutomotiveCo reported its recent ERP and MES joint adoption processes, aiming at integration, along with its failed attempt to integrate with PLM. AgricultureCo1 has already employed an MES system for eight years, but there was no integration with other systems. When assessing market options to acquire a new MES for vertical integration, AgricultureCo1 chose to adopt a systems architecture and build its own customized MES, and so did AutomotiveCo2. Each case study company is at the maturity level of obtaining visibility (Schuh et al., 2020a) from the vertical integration.

\subsection{Research Instruments and Data Collection Procedures}

To identify the factors that influence the adoption of information systems for vertical integration, and their dynamics, semi-structured interviews were used as the primary data collection method. An initial version of the interview script was tested with two participants from different companies and then revised before the main interviews were conducted (see Appendix 1 for the interview script). We then interviewed key representatives who participated in 
Table 2 Background of the cases

\begin{tabular}{|c|c|c|c|c|}
\hline Case company & Description & Size & Sector & Interviewee's role \\
\hline AutomotiveCo & $\begin{array}{l}\text { Multinational company in } \\
\text { road implements }\end{array}$ & $\begin{array}{l}\text { Multinational }(+12,000 \\
\text { employees })\end{array}$ & $\begin{array}{l}\text { Motor vehicles, trailers and } \\
\text { semi-trailers }\end{array}$ & $\begin{array}{l}\text { Automation Engineer; } \\
\text { Operational Director; Digital } \\
\text { Manufacturing Engineer }\end{array}$ \\
\hline VehicleCo & $\begin{array}{l}\text { Brazilian national company in } \\
\text { automotive equipment }\end{array}$ & Medium (+2000 employees) & Machinery and equipment & Industrial IT Specialist \\
\hline ElectronicCo & $\begin{array}{l}\text { Multinational company in } \\
\text { electronic materials and } \\
\text { components, accessories for } \\
\text { data recording and storage. }\end{array}$ & $\begin{array}{l}\text { Multinational (+100.000 } \\
\text { employees) }\end{array}$ & $\begin{array}{l}\text { Computers, electronics and } \\
\text { optical products }\end{array}$ & $\begin{array}{l}\text { Process Engineer; } \\
\text { Industrial Engineer }\end{array}$ \\
\hline PowertoolsCo & $\begin{array}{l}\text { Multinational company in } \\
\text { portable power tools }\end{array}$ & $\begin{array}{l}\text { Multinational }(+17,000 \\
\text { employees })\end{array}$ & Machinery and equipment & $\begin{array}{l}\text { Industrial Planning Specialist; } \\
\text { Process Analyst; } \\
\text { Production Manager }\end{array}$ \\
\hline AgricultureCo1 & $\begin{array}{l}\text { Multinational company in } \\
\text { agricultural equipment }\end{array}$ & $\begin{array}{l}\text { Multinational }(+20,000 \\
\text { employees })\end{array}$ & Machinery and equipment & $\begin{array}{l}\text { IT Manager; } \\
\text { Manufacturing Manager; } \\
\text { Process Engineer }\end{array}$ \\
\hline AgricultureCo2 & $\begin{array}{l}\text { Brazilian international } \\
\text { company in agricultural } \\
\text { equipment }\end{array}$ & Medium (+500 employees) & $\begin{array}{l}\text { Motor vehicles, trailers, and } \\
\text { semi-trailers }\end{array}$ & $\begin{array}{l}\text { Industrial Director; } \\
\text { Process Engineer }\end{array}$ \\
\hline TerminalsCo & $\begin{array}{l}\text { Brazilian national company in } \\
\text { equipment for terminals and } \\
\text { handling of solid bulk }\end{array}$ & Medium (+1000 employees) & Machinery and equipment & $\begin{array}{l}\text { Industrial Engineering Super- } \\
\text { visor; } \\
\text { Engineering Coordinator }\end{array}$ \\
\hline ChemicalCo & $\begin{array}{l}\text { Multinational company in the } \\
\text { chemical and petrochemical } \\
\text { sector }\end{array}$ & $\begin{array}{l}\text { Multinational }(+10,000 \\
\text { employees })\end{array}$ & Chemicals & $\begin{array}{l}\text { Automation Engineer; Indus- } \\
\text { trial Engineer }\end{array}$ \\
\hline AutomationCo2 & $\begin{array}{l}\text { Multinational company in } \\
\text { automobiles and commer- } \\
\text { cial vehicles }\end{array}$ & $\begin{array}{l}\text { Multinational }(+10,000 \\
\text { employees })\end{array}$ & $\begin{array}{l}\text { Motor vehicles, trailers, and } \\
\text { semi-trailers }\end{array}$ & $\begin{array}{l}\text { Industry } 4.0 \text { Head; } \\
\text { Process Engineer \& Industry } \\
\text { 4.0; }\end{array}$ \\
\hline ClothingCo & $\begin{array}{l}\text { Brazilian national company in } \\
\text { clothing }\end{array}$ & Medium (+1600 employees) & Textiles & $\begin{array}{l}\text { Industrial Engineer; } \\
\text { IT Analyst }\end{array}$ \\
\hline
\end{tabular}

the adoption of information systems for vertical integration, including IT managers and industrial engineers (see Table 2), as well as officers actively involved in the strategic decisions related to Industry 4.0 in the companies. Each interview lasted around 1:30 $\mathrm{h}$ and was conducted by videoconference or in person at the firm.

We recorded the interviews and wrote notes on participants' impressions and comments during data collection. The notes were made by four researchers, which allowed us to confront interview impressions and obtain a complete view of each case while reducing observer bias (Yin, 2009). After analyzing the interview transcripts, we conducted a new round of interviews with the same respondents to clarify details or questions that remained from the first round. Finally, to enable data triangulation, we reviewed documents made available by the companies (internal procedures, business reports, and internal slideshows), information from their websites, past research carried out in these companies by other researchers on Industry 4.0-related subjects. We also visited some firm sites (only for AutomotiveCo, AgriculturalCo1, and AgriculturalCo2, due to COVID-19 pandemic restrictions) to understand how their systems operate in practice. The entire data collection process was carried out from September 2019 to September 2020.

\subsection{Data analysis - Validity, Reliability, and Interpretation}

For construct validity, the items in the questionnaire script were assessed and complemented with the help of four researchers specialized in Industry 4.0 who did not participate in the data collection process. Additionally, the first round of interviews was conducted with two companies to fine-tune the instrument. In terms of external validity, we conducted multiple case studies and compared the evidence in selecting large companies adopting information systems for vertical integration. As for reliability, a case study protocol was used, and a final report was prepared based on the transcript of the recorded interviews. Some of these procedures have been described in Sections 3.1. to 3.2.

Regarding data analysis, the first step was to transcribe recorded interviews. After transcribing all the interviews, the data were analyzed, looking for evidence of factors influencing the adoption of information systems for vertical integration. The evidence was structured and organized in a final 
report. After analyzing each interview individually, identifying isolated factors and behaviors, we also performed a cross-case analysis to recognize similarities, contrasts, and patterns between the cases. Finally, we made a second contact with the same interviewees to report our conclusions and collect feedback about our interpretation, as well as new information in cases where divergences existed.

\section{Results}

The data collected in the interviews provided information to detail the factors that influence the adoption of information systems for vertical integration in manufacturing. In this section, the factors are identified and described following the conceptual research framework presented in Fig. 1, i.e., for each context of the Technology, Organization, and Environment (TOE) framework, we analyze the step of the innovation-decision process model.

\subsection{Technological Context}

During the knowledge phase, most of the companies (AutomotiveCo, VehicleCo, ElectronicCo, PowertoolsCo, AgricultureCo1, AgricultureCo2, AutomationCo2, ClothingCo) looked for information systems that could be acquired in modules and assembled according to their individual needs, especially when considering ERP and MES systems. These companies were unwilling to purchase the full information system, but only specific modules that would be useful for their operation aiming to achieve vertical integration in their operations, such as modules for logistics, maintenance, quality, manufacturing control, etc. As expressed by the specialist of VehicleCo: "We needed an ERP for our vertical integration process that might be customized for the tire production environment, with its particularities in the way it traces, the type of data collection, the type of batch control, etc.". Therefore, customization was a key factor for these companies.

A second factor was technology expansion capacity. This factor was highlighted by AutomotiveCo, AutomationCo2, ClothingCo, and AgricultureCo2 because the chosen information system had to be robust enough to support the company's long-term expansion plan. For instance, one of the reasons why AutomotiveCo decided to buy a new ERP system for vertical integration was that the old ERP system could not support the company's growth in the following years to accomplish new Industry 4.0 demands like real-data intensity and communication with other information systems. As expressed by the company's Operational Director: "the two ERPs we had (in different units) would not support our expected growth, as the managers at the time did not consider this. Thus, the IT department has now found that these systems would struggle to support growth in terms of the volume and scale of the company data". Similarly, ClothingCo reported adopting an MES system to support the plant's growth. "We needed to grow in our manufacturing field and increase efficiency, and so we needed tools for that (MES) - also to increase production capacity" (Industrial Engineer). The company expansion achieved by improved vertical integration results in more data from different manufacturing activities. This higher amount of data needs to be processed in real-time to meet the operational requirements of vertical integration systems. Besides, the more a company grows, the more people will need simultaneous access to different information sources and hierarchical layers, which will demand a higher level of accessibility to the systems. Lastly, additional system modules may be required, as expressed by Jain et al. (2008), who highlighted that the company is looking for systems that help integrate the operational activities in real-time with other activities such as supply chain and marketing better prepare its production capacity.

As a third factor, we observed that interoperability highly influenced the companies adopting information systems for vertical integration. Interoperability means providing continuous communication between information systems, devices, and applications. Interoperability features are essential for building integrated business systems. As expressed by the digital manufacturing engineer of AutomotiveCo, "since we look for vertical integration, we said no to those providers whose MES was not able to communicate with our ERP. Also, we no longer buy equipment whose builders have restrictions about opening their protocols to connect with the information systems of other brands". Similarly, AutomationCo2 reported that it was necessary to adapt much of its machinery to have the same communication protocol to achieve vertical integration: "We needed to do much work in the standardization of machines and equipment so that everyone can communicate". This effort made by the company was considered a negative factor that it wishes to avoid in the following steps of vertical integration.

In the persuasion phase of the adoption process, the company deepens its knowledge of information systems for vertical integration by studying each technology and supplier's pros and cons. At this stage, cybersecurity was mentioned as an important decision factor by the companies ChemicalCo, AutomationCo2, ElectronicCO, and PowertoolsCo for the successful vertical integration of systems. A demand for vertical integration is the integration of Information Technology (IT) and Automation Technology (AT). For a long time, these technologies have been decentralized; they have had different objectives and hierarchies. In this new scenario, cybersecurity is essential to keep data and digital processes safe from cyberattacks that could stun the production lines. As expressed by PowertoolsCo: "one of the 
main requirements in adopting MES and integrating it with other systems was the issue of network security due to the integration of the information technology layer with automation technology". In this sense, the more verticalized the integration of systems is, the more vulnerable they become to cyberattacks. Therefore, system security is a key element to be considered by the interviewees.

Additionally, the current architecture undoubtedly influences the adoption of specific information systems for vertical integration, as mentioned by all companies interviewed. The architecture defines the software components, their external properties, and their relationships with other software. Each manufacturing company has different applications, tools, and systems, depending on their specific history and needs; thus, there can be a wide range of combinations of these components. Behind each combination, a large organizational structure called software architecture is responsible for carrying out the strategic analysis of these components. To implement vertical integration is necessary to analyze whether the intended new system can be integrated with those existing in the company's current architecture. This strategic analysis can take years, as was the case with AgricultureCo1, which had to redesign its architecture worldwide before adopting a new MES to complete its vertical integration process: "Software architecture is a real puzzle, and it is necessary to evaluate it carefully for a successful adoption of vertical integration".

Another factor is the choice of functionalities for each information system. Different systems, such as ERP and MES, have some functionalities in common, and it is up to the company to choose which one it will use. According to the interviewee from AgricultureCo1, the ERP they had in the company already included some features proposed by the intended MES, so a study was carried out to understand which functionality would be the most suitable for each system: "we decided that our MES should include all features of four pillars: planning, logistics, quality, and maintenance". Similarly, the information system of AutomationCo 2 was developed over time for different functions, such as quality and maintenance. Therefore, the MES was developed with only the necessary functions (manufacturing control and process). However, AutomationCo2 also developed its MES to be a "data lake" for the integration of all systems: "At the manufacturing execution level, we created a data lake to integrate all systems already running in the factory”.

At this stage, a fourth factor in the technological context is the platform characteristics that information systems require for vertical integration. In recent years, several studies have highlighted the importance of platforms for Industry 4.0 in order to create an ecosystem of solutions for different applications in the company. In this sense, a platform can be defined as a set of subsystems and interfaces that form a common structure. Companies can efficiently develop and produce a line of products derived from these subsystems. Several companies (AutomationCo2, AgricultureCo1, AgricultureCo2, PowertoolsCo, and ElectronicCo) pointed out that the platform factor was influential in adopting information systems for vertical integration. As reported by PowertoolsCo: "We had four MES solution alternatives. We opted for a platform solution that provides scalability, integration with other systems, and which provides a greater degree of freedom than traditional MES". A similar approach can be observed in the statement of ElectronicCo's interviewee: "the first thing that was taken into account was that it was a platform and not a restricted system because we could grow in the future; the possibility of integrating with other systems, especially with the ERP and its integration with APS ${ }^{1}$, integration with supervision systems and the interface with machines has always been a concern".

The last phase is the adoption process. The firms engage in more practical activities to decide whether to adopt or reject the information systems for vertical integration. Since after this phase, the firm will incur in investments, the technology costs should be clear and the supplier. Trialability is another important characteristic that firms should observe. It refers to the ease with which customers can try out a new product or service. The trialability of information systems in small proof of concepts or pilot projects was demanded from technology suppliers by AutomotiveCo, ElectronicCo, ClothingCo, AgricultureCo2, AutomationCo2, ChemicalCo, and AgricultureCo1 to test and learn about the connectivity and integration problems that could arise and could not be predicted in theory. As stated by the Digital Manufacturing Engineer from AutomotiveCo: "we have a production line that we generally use to test technologies of this type. Then, the suppliers present their solutions, and from this experience, we make our final decision". Similarly, ClothingCo tested its information system for three weeks before deciding for its implementation, and AgricultureCo2 tested the connectivity of IoT with the MES and its functional areas: "the MES is being tested in 3 sectors of the company and, if successful, we plan to adopt it in one year for the whole company". In a different strategy, to have less impact on its current activities, AgricultureCo1 tested different parts of the vertical integration in different plants worldwide: "it gave each region an action for research and development. 'Fail fast, learn faster' is our philosophy for these initiatives. Then, the smart factory committee shares all research and learnings, and then the initiatives become global standards".

\footnotetext{
1 APS is a type of information system to plan and schedule production based on available materials, labor, and plant capacity.
} 


\subsection{Organizational Context}

In the knowledge phase, we observed that the infrastructure factor stood out in most companies (AutomationCo2, AutomotiveCo, VehicleCo, ChemicalCo, ElectronicCo, AgricultureCo1, ClothingCo, AgricultureCo2). In order to adopt an information system for vertical integration, like MES, for instance, much equipment, sensors, and a network structure are required to support it. Besides, depending on the chosen system, it demands a specific infrastructure for integration. For instance, the IT Manager of AgricultureCo1 reported that they needed to adapt the factory's infrastructure to integrate the new systems: "Every infrastructure modification we made in the site was because we would have to integrate the MES from Brand $\mathrm{X}$ with our ERP, which is from the Brand $\mathrm{Y}$, so we would have much integration work to do here by ourselves. “

Additionally, the firms' legacy factor was mandatory when deciding which information system to adopt for vertical integration. None of the companies interviewed is starting their systems implementation from a greenfield; thus, they already have a legacy of previous systems running in their factories. As expressed by AutomotiveCo: "we did not look for the best MES, but for an MES that we would be able to integrate with the different legacy systems that we have in our many factories".

In the persuasion stage, firms should observe the relationship of the information system with people. In this sense, the organization's digital culture was identified in our interviews as a factor that influences the adoption of information systems for vertical integration in companies like AutomotiveCo, AutomationCo2, VehicleCo, AgricultureCo1, ClothingCo, andAgricultureCo2. As a counterpoint, ElectronicCo considered that they were unsuccessful in adopting an APS software for their vertical integration process because they neglected aspects such as their employees' culture and readiness to use digital tools. Therefore, they used a different approach for the adoption of MES: "When we implemented the APS software project, we were very much concerned with the technical part and little mindful of the organizational and cultural part. The system was ready and beautiful, but nobody used it; it was a money pit; until today, they use excel. In the MES project, which was a little later, we did it very differently; when we closed it, we involved many people from various areas in helping us define the requirements. " As this example shows, people's engagement in the company's digital transformation process was considered essential for these companies to integrate the systems of different company layers. Additionally, AutomotiveCo explained that there are difficulties in changing behaviors regarding innovation because they have a long-established tradition in the company. As the interviewee from this company affirmed, "For people that are used to making decisions based on experience, making decisions based on data or technologies is a challenge". According to the interviewee, it is necessary to promote the benefits of vertical integration so that everyone will be aware of the whole when acquiring any new technology/equipment. Also, VehicleCo reported that this conservative culture pervades all areas, from IT to the shopfloor: "sometimes we forget that an information system for vertical integration impacts the entire company, and there are divisions within the IT area itself; so, for you to be able to form a team and get it to work and understand certain differences and sometimes even create parallel systems, not necessarily integrated, it is still a very difficult task, especially when managers have more conservative concepts, even about IT... so there is a convincing job to be done. But the greatest difficulty for us to overcome the cultural issue is really on the factory floor". To deal with this factor, AutomationCo 2 implemented forums to introduce Industry 4.0 and vertical integration concepts to its employees: "we held forums with more than 400 employees to show Industry 4.0 and its benefits. We spread a new culture to facilitate adoption", affirmed the Industry 4.0 Head. Something similar happened at ClothingCo: "training was needed to raise awareness of the change and explain what the company is pursuing with the adoption of vertical integration".

In parallel with the cultural factor that observes people's openness to the change brought by the information system for vertical integration, firms should be aware of people readiness, that is, if employees have the knowledge and capabilities to manage the new information systems and the data they generate. As expressed by AutomotiveCo: "we put our MES to run without giving proper training to our employees. Because of this, the company almost stopped. It was chaos! After one week, we needed to come back to our old system, and the credibility of the project was highly impacted". For ClothingCo, more than training the current employees, they needed to hire new professionals to extract results from the data generated by the vertical integration. At ChemicalCo, they created an entirely new department to deal with the data and coordinate projects related to digital technologies. Something similar happened at PowertoolsCo: "we needed to create a new department when we realized that the MES is not a project with a beginning, middle, and end. The MES project has no end. It is a project that does not belong to any specific sector; it belongs to everyone simultaneously". This new department at PowertoolsCo was designed to provide vertical integration systems to the whole company and is mainly composed of IT and production staff. This also brings a new factor into play, the integration between functional areas, which companies should be aware of in this persuasion stage. PowertoolsCo, AgricultureCo1, AutomotiveCo, and ElectronicCo acknowledged that they could implement vertical integration only because they could involve different functional areas and consider each other's demands when 
building the system. At PowertoolsCo, a key person from each sector was interviewed to determine what exactly the new system would affect.

In addition to the people who will use the information system, IT department readiness was also highlighted by AutomotiveCo, ElectronicCo, PowertoolsCo, ChemicalCo, and AgricutureCo1. Most companies still have their IT departments functioning traditionally, only providing support for the rest of the organization, with standardized solutions for computers, phones, and software. This type of traditional IT department is usually not prepared for large investments in Industry 4.0. The vertical integration demands integrating the IT department with the production and development processes requires knowledge of IT and AT, and specific knowledge regarding other functional areas of the firm to be integrated with the vertical integration. At AgricultureCo1, the IT area was divided into three sectors because of vertical integration: "we now have an IT area divided in (i) finances and sales, (ii) human resources and supply chain and (iii) manufacturing and engineering. I am responsible for the third. It encompasses all projects involving IT and AT in the areas of manufacturing and engineering”.

Regarding the persuasion stage, the lack of standards for systems was a factor raised by the companies AutomotiveCo, AutomationCo2, VehicleCo, PowertoolsCo, and AgricultureCo1. Industry 4.0 is connecting factories, making machines and systems communicate and share data. A standardized form of communication between these systems is desirable to reduce the need to convert data. With a standardized way of defining and communicating data, it would be much easier and faster to adopt the concepts of vertical integration. However, there is currently no industry-wide standard for industrial communication systems. According to AutomotiveCo, communication between new technologies and all existing systems and machines is a complex task, requiring translation of communication protocols between all parties, as mentioned above. The lack of a standard for digital manufacturing systems causes confusion and insecurity when adopting an information system for vertical integration. According to PowertoolsCo, the ISA-95 standard is still insufficient, which presents a benchmark for companies, including integration issues, terminologies, and process models. Although the ISA-95 standard provides a generic map of all processes and their data flows, some activities are not covered by the standard. The project team is responsible for evaluating the company in question and making decisions. In the case of AgricultureCo1, they reported that they needed to carry out an entire study, which took about a year and a half to complete, to define the company's IoT information protocols that would allow data to be collected from any machine or equipment in an organized manner.

A final factor mentioned by the companies AutomotiveCo, VehicleCo, AgricultureCo1, and AutomationCo2 was the need for specialized external expertise to support adopting information systems for vertical integration. AutomotiveCo hired a specialized consultancy to support its ERP system choice due to the firm's know-how, personalized service, and the possibility of frequent iterations in seeking an adequate solution. They also partnered with a university to support a research group and hired a Ph.D. student to dedicate exclusively to the investigation of vertical integration. Although AgricultureCo1 did not hire a consultancy to guide the entire adoption process, they hired a specialized systems architect to design its MES, as mentioned earlier.

In the decision stage, the pilot projects and proof of concepts provide more reliable information to analyze the benefit-cost tradeoff, one of the most important factors in the firms intending to adopt the systems. Eight of the nine firms considered the economic analysis particularly important to make an adopt or reject decision. However, AgricultureCo2, AgricultureCo1, and AutomotiveCo noted several aspects of a cost-benefit analysis that are difficult to measure in monetary terms for vertical integration, as expressed by AutomotiveCo: "It is complicated to measure the cost-benefit of the systems. We do an extrapolation analysis (technical and financial analysis). For example, in the case of MES: we counted the number of terminals that we would have in this operation, connected machines, televisions, computers, etc. So, we extrapolate, in 5 years we will have more or less than many".

Finally, we observed the importance of involving top management in the adopt or reject decision. While most of the analysis in the previous stages was concentrated in lower organizational levels, top management support is a critical factor influencing the adoption of information systems for vertical integration. Top managers should be the supporters and give legitimacy to the many changes people in the organization will need to adapt to during the information system implementation. Thus, all results from the innovation-decision process should be presented to them for approval. For instance, the interviewees from AutomotiveCo pointed out that the adoption decision came as a common agreement between administrative and industrial top managers, even though its president has an innovation and technological bias that is positive for such projects.

\subsection{External Environment Context}

In the knowledge phase of the adoption process, the competitive pressure was identified by AutomotiveCo, AutomationCo2, AgricultureCo1, and ChemicalCo, as an important factor for the adoption of information systems for vertical integration. To seek competitive advantage in a competitive global market, organizations strive to adopt innovations, searching for new alternatives to improve their production and face the 'technological 
Fig. 2 Empirical framework summarizing the factors of the process for adoption of information systems for vertical integration

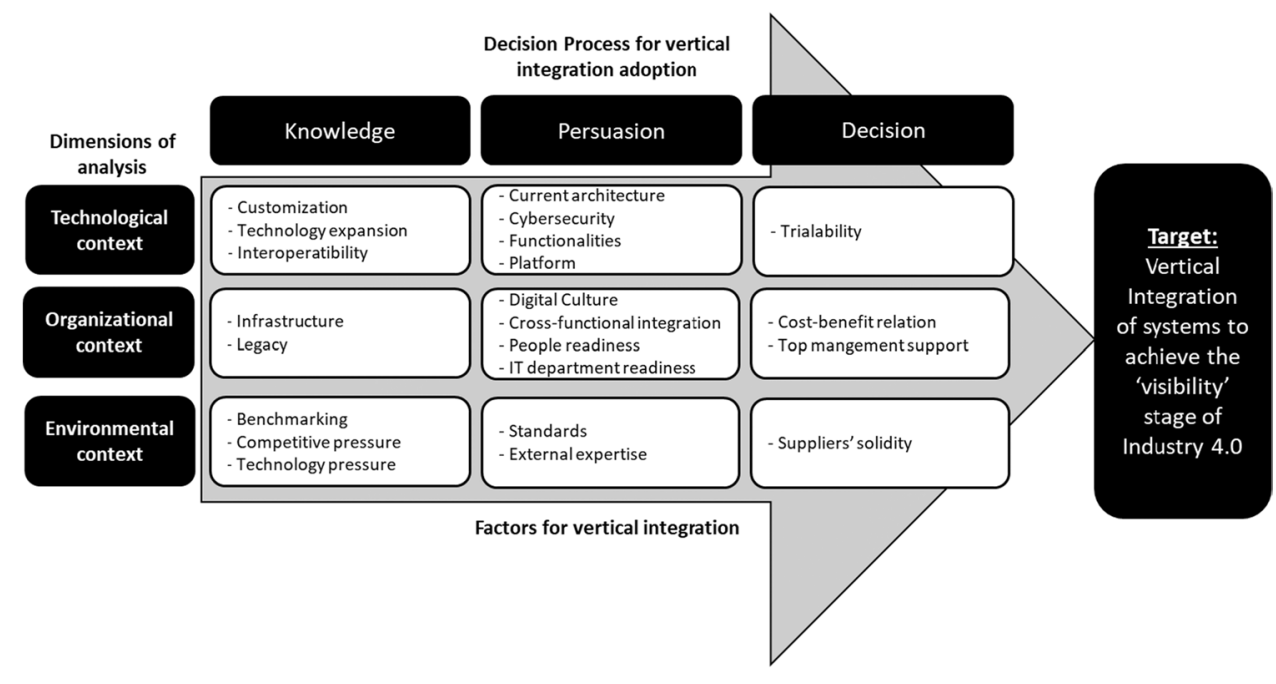

race' in Industry 4.0 context. ChemicalCo interviewees, for instance, revealed a great concern for the company not to "be left behind" by competitors, considering strategical to invest in Industry 4.0 concepts and technologies. However, this competitive pressure does not come only from competitors but may also come from other units in the company. For example, PowertoolsCo and AgricultureCo1 reported that top local managers feel pushed to adopt information systems for vertical integration since other units implemented them.

Besides, a technology push factor was noticed influencing the adoption of information systems for vertical integration in AutomotiveCo, ElectronicCo, PowertoolsCo, ChemicalCo, and AgricultureCo1. These companies have a constant concern about knowing all innovations available in the market, keeping regular contact with traditional technology suppliers, and startups that develop software or new products that are part of the vertical integration. At AutomotiveCo, they created a prospection team formed by IT and production staff to seek news on digital technologies, visit suppliers, and participate in trade fairs.

In the persuasion phase, interviewees from AutomotiveCo, AutomationCo2, ElectronicCo, PowertoolsCo, AgricultureCo1, ChemicalCo, and TerminalsCo recognized benchmarking as a crucial factor since they needed to monitor their competitors to learn about the technologies they are using. As exemplified by the case of AutomotiveCo: "in the case of PLM and MES, we carry out benchmarking to select potential technology suppliers. We visited four companies to see which brand of information system they were using and get feedback. It was not to check they were using MES or not, because we were already sure that we needed an MES". On the other hand, TerminalsCo reported that they only realized the need for a vertically integrated MES system after benchmarking: "from visits to other companies, we realized that they were using a vertically integrated MES and reported many benefits from it. So, we decided to go to the market to look for this kind of information system".

Finally, in the decision stage, suppliers' solidity was mentioned as a crucial factor by AutomotiveCo, ElectronicCo, ClothingCo, and AgricultureCo1. While in the previous stages, the firms were more interested in understanding the characteristics of the information system, at this stage, they are more concerned about receiving adequate support from the systems suppliers during and after implementation. "The managers have the following vision: Is the supplying company solid? Is it global? Can it serve several plants around the world? Will we be well supported over time?" (Digital Manufacturing Engineer from AutomotiveCo). Thus, even though AgricultureCo1 and AutomotiveCo tested some vertical integration concepts with startups to understand their pros and cons, in some cases, they ended up choosing another multinational supplier for the information systems implementation. On the other hand, since ClothingCo has only one factory, it has a different opinion about working with small firms: "Three suppliers met our requirements: two were big, well-established firms and one was a startup. However, the startup cost six times lower than one supplier and three times lower than the other. The startup can offer support only for our region (50km radius). Also, as a smaller company, it was interested in gaining commercial know-how by selling us the MES; so that would benefit both sides" (Industrial Engineer). However, ClothingCo also demonstrated some concern about its supplier choice: "small firms have a small structure, and they cannot serve us as quickly as we would like."

\subsection{Summary of the Findings}

We summarize the main factors identified in the case studies in Fig. 2. As shown in this figure, the factors of each TOE dimension change over time according to each stage of the 
innovation-decision process. The following section discusses the implications of such findings, showing the main patterns behind the adoption process described for vertical integration in the Industry 4.0 context.

\section{Discussions}

The results summarized in the consolidated framework in Fig. 2 can be analyzed either from the perspective of each TOE dimension along the different stages or from the perspective of each decision stage considering the nuances of the different dimensions analyzed. We opted for the second option (i.e., an analysis of each of the columns of the framework in Fig. 1). Our discussion also aims to explore tensions between the different factors identified in our case studies.

The Knowledge stage (Fig. 1) shows that the implementation of vertical integration is strongly dependent on the resources currently available in a company's manufacturing activity, meaning that it is a kind of incremental innovation process for the information system adoption (Pérez-Lara et al., 2018). This is evidenced by the fact that even when the environmental context presents external pressures for the advancement in the Industry 4.0 implementation, the internal condition of the information systems layers plays a key role in the vertical integration process. Our results evidenced that companies strongly depend on a fragmented technological legacy and look for customized technologies and systems interoperability because they already have several parts of the technology solution when they decide to advance towards vertical integration. The innovation literature has suggested that this is the usual approach taken by companies with consolidated resources: they tend to rely on what they already have and take a new step toward a more innovative approach (Cortimiglia et al., 2016). This is also understandable since Industry 4.0 solutions frequently come from different providers, which must be interconnected to configure an integrative solution. Therefore, it is easier for companies to start from the already established systems in their companies (Benitez et al., 2021). However, such an approach can also present some challenges for vertical integration in the Industry 4.0 domain. As shown by Frank et al. (2019), many companies face difficulties in implementing a flexible manufacturing system during the Industry 4.0 journey because they rely too strongly on an internal legacy of systems and structures established before the company aimed to advance in the Industry 4.0 concept. Therefore, while the organizational context can limit the company's expansion due to the legacy and infrastructure, companies pursuing vertical integration should balance this with the environmental context, which brings the external needs and trends. In such a scenario, factors of the technological dimension in this stage can play a moderating role since the look at future expansion, customization, and interoperability can help better connect the external needs with the already established resources (Ali et al., 2021; Javidroozi et al., 2020).

At the Persuasion stage (Fig. 2) in the decision process, we could observe another type of concern regarding the factors identified for vertical integration. These factors consider operational concerns companies may have for the implementation of the technological solution. Cybersecurity was already observed in the literature as a factor limiting firms' willingness to advance in the vertical integration of systems because of concerns about being hacked and suffering impacts on their production activities (Qian et al., 2012). Furthermore, functionalities and platform issues must be constantly managed by companies to ensure that the information system will operate correctly (Jain \& Bhattacharyya, 2012). Similarly, human-related concerns like culture, integration between sectors, people readiness, and external parties' support also represent operational characteristics of information systems adoption (Javidroozi et al., 2020). These factors also reinforce the highly relevant role of people in the path of firms towards Industry 4.0 (Meindl et al., 2021; Romero et al., 2020), suggesting that companies can make mistakes when they implement technology programs without putting people at the center of this process. Such factors can be observed in adopting any information system, but they become particularly relevant in the Industry 4.0 context. In this sense, it is important to bear in mind that vertical integration represents a major integration of different layers of systems, including SCADA, MES, ERP, and sometimes also APS, PLM, and other applications, that are used in the most diverse firm departments, not only in the manufacturing sites (Antonio et al., 2017; Longo et al., 2017; Rossit et al., 2019). In this sense, any problem related to factors like cybersecurity or unsuitable functionalities (Technological context), or lack of workers' engagement in their use (Organizational context), or lack of external partners' support in the event of a problem (External context), can become a systemic information problem for the company. Kahle et al. (2020) demonstrated that the creation of digital ecosystems with the participation of several stakeholders for the provision of expertise, standards, and cybersecurity rules for companies that adopt Industry 4.0 technologies could help to advance faster in this kind of adoption, which is consistent with this stage of our framework. Moreover, external support is essential at this stage because most companies may not have all the internal skills and resources to implement advanced systems due to a lack of people and IT readiness for digital transformation (Benitez et al., 2020). Consequently, while the previous stage was marked by the tensions between internal and external demands for vertical integration, this new stage needs to balance vertical integration's technology and social requirements. 
Fig. 3 Main tensions between the factors identified in the study for the vertical integration of systems

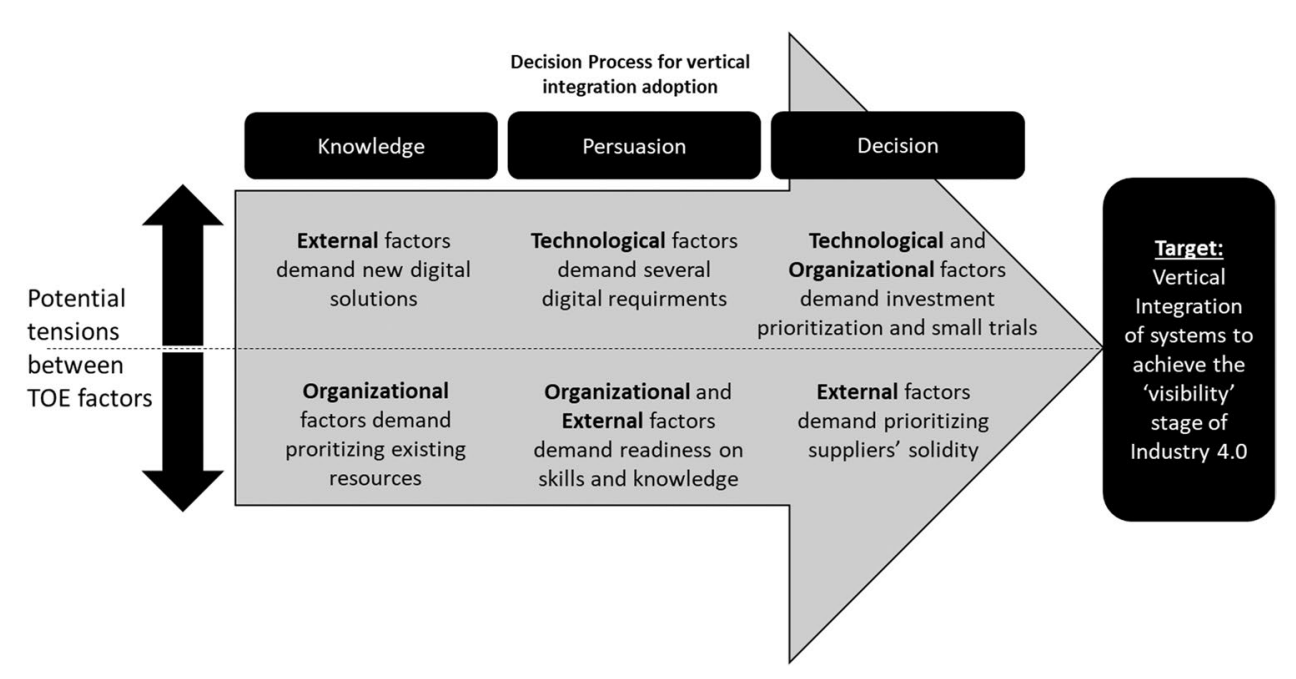

At the third stage, Decision, our findings point to fewer yet not less important factors. We show that some companies are more willing to prove concepts and testbeds before implementing the full, costly solution (Technological context). As the literature highlights, investments in Industry 4.0 are hard to assess because of their complexity (Margherita \& Braccini, 2020), and therefore proofs of concepts are essential to visualize the real cost and investments of a broader implementation of vertical integration systems. Many of such proofs of concepts can be performed through the involvement of startups in the Industry 4.0 development (Alam \& Khan, 2020). However, as shown in our findings, this can also be challenging for the future scalability of the solution since startups may not have the necessary operational capacity to extend the solutions to the whole company, especially when the company is a large one (Marcon \& Ribeiro, 2021). Therefore, suppliers' solidity is equally important since the vertical integration journey can be long and demand much energy from both the company and the provider for integration of processes and systems that will provide a real-time data flow across the different hierarchical layers of the company (Saghiri \& Wilding, 2021; Salam, 2019). In such a scenario of costs and demands, implementing vertical integration information systems can be a 'painful' process that firms will resist for as long as possible (Matyoqubov et al., 2020). Besides, losing the support of a technology provider during this journey can jeopardize the entire project. In such a case, suppliers' solidity is usually associated with larger companies and more costly technology solutions for the Industry 4.0 context (Benitez et al., 2020). Therefore, companies may have to deal with a tradeoff between smaller and cheaper solutions for testing vertical integration concepts in specific parts of the process and acquiring broader, more robust solutions that will be more expensive and fit for the long journey of a full vertical integration process.
We summarize our discussion above in Fig. 3, where we represent the main tensions between the different factors and dimensions that managers may have to deal with during the adoption of systems for vertical integration. As shown in this figure, in the Knowledge stage, managers will face a tension between the demand for new digital solutions in the factory, especially pushed by external competition, and the internal concern of preserving and prioritizing the legacy of information systems already in place. Then, in the Persuasion stage, managers need to balance between the several technical requirements for the digital transformation and the social factors that need to be prepared to follow this transformation. Lastly, at the Decision stage, from a technological and organizational perspective, the investment in small, low-budget trials, usually available from startups, can be a good option for companies to start the Industry 4.0 vertical integration journey. On the other hand, even this journey will be long and challenging, making larger suppliers a sounder source to support the companies' expectations in the long run.

\section{Conclusions}

Our findings provide the big picture of different factors that managers should consider during the decision-making process. Our study adopted the innovation-decision process view and the TOE framework to provide a conceptual understanding of what companies consider to adopt systems for vertical integration, aiming to achieve the visibility stage of Industry 4.0. Using data from the case studies analysis, we developed a framework that describes the main factors involved in the decision-making process for adopting systems aiming for vertical integration. We showed these factors deployed in three main stages of decision: knowledge, persuasion, and decision, and in three main dimensions of 
analysis: technology, organization, and environment. We summarized 22 main factors distributed along these stages and dimensions of analysis (Fig. 1).

\subsection{Theoretical Contributions}

The information systems literature has largely discussed technical and organizational factors for the adoption of information technologies. However, this is the first attempt to provide understanding in a specific type of information system which considers the integration of different technologies such as SCADA, MES, APS, PLM, and ERP to implement vertical integration in the Industry 4.0 context, i.e., when real-time data flow based on IoT systems is used. The novelty of this view is that we considered an interrelated and complex system of different information technologies that demands a broader set of requirements than in the study of single technology adoption, including various technical, organizational, and environmental factors. Moreover, this study demonstrates that such diversity of factors must be considered alongside the technology adoption process' stages. While previous studies have considered Industry 4.0 implementation factors from a static perspective (e.g., Sony and Naik, 2019; Hoyer et al., 2020; Nimawat and Gidwani, 2020; Lin et al., 2019), this is the first study investigating the dynamic aspect of the implementation that information system managers need to consider. This combination of the technology adoption process with the TOE framework is a novel contribution to the literature. It provides a conceptual framework that scholars can adopt for any other type of information system analysis. Thus, our study clarifies vertical integration factors and provides a broader conceptual contribution related to these factors for the general information system literature. Another contribution of this study is that such complex integration of different information technologies creates tensions between the factors alongside the adoption process. We showed which are these tensions and how they relate with each other, highlighting factors from different sociotechnical dimensions that can conflict to each other. Information management scholars can find in this analysis of tensions opportunities for future research since the origins and approaches to manage such different tensions can be investigated to create more theory on the sociotechnical aspects for the adoption of vertical integration.

\subsection{Practical Contributions}

Our results also provide practical contributions for managers, and we provide some guidelines regarding these contributions in this section. Our study showed that, at the knowledge stage of adoption, there is a need for new digital solutions demanded by external factors. In contrast, the company's need to prioritize its internal organizational resources creates tensions between what the company has and what the company needs. In this sense, managers need to balance the use of legacy systems and the reengineering of the company's infrastructure. This is more important in vertical integration because it considers several information technologies that have been acquired in different moments of the company's evolution. Therefore, practitioners must consider the feasibility of such integration between the legacy systems and the new technologies and the resulting flexibility or rigidity of the resulting vertical integration. Since Industry 4.0 requires more flexibility, managers need to take care about verticalizing systems that will result in organizational rigidity due to the lack of functionalities for Industry 4.0 demands.

Secondly, we showed a tension between digital technological requirements and the need for readiness in terms of organizational skills and knowledge in the persuasion stage. Although they are not necessarily in tension, managers can easily focus only on the technological aspects and dismiss social factors. As our results showed, vertical integration in the Industry 4.0 context is a multidimensional and multifunctional implementation of information systems and needs a coherent balance between such sociotechnical factors. Thus, managers need to develop training programs, digital culture development programs, and skilled human resources recruitment as the vertical integration advances in its implementation.

Finally, in the decision stage, there is a tension between the need to develop small trials and prioritize investments and the company's need for technology suppliers' solidity, which is usually associated with large companies offering large technology platforms. Prior studies (e.g., Benitez et al., 2020, 2021; Kahle et al., 2020) suggested that one of the options for managers in such case is to orchestrate a group of companies through an ecosystem approach, which is one of the most prominent approaches in the Industry 4.0 domain. Such an approach allows integrating the complexity of the demands around several small and medium-sized actors that can help create the required environment for small trials. At the same time, there is still solidity due to the ecosystem architecture in which the company does not depend on a single supplier for such an implementation.

\subsection{Limitations and Future Research}

Our study also has limitations and opportunities for future research. We did not analyze any of the companies after the vertical integration process was completed. Since Industry 4.0 presents an interrelated set of technologies and solutions, success in the future stages of implementation could be a good measure of how vertical integration was adopted and implemented. For instance, the quality of the data analyzed or the ability of a company to make good predictions 
depends on how well its systems were integrated to provide the data that will support decision-making. Therefore, future studies could analyze the post-implementation stage of vertical integration to make a backward analysis and assess how successful the vertical integration was and the potential weaknesses in such implementation. Another point is that we only analyzed the adoption stage without regard to the final financial process involved in choosing the best possible systems and their form of implementation. Future studies can provide tools and elements that will facilitate decision at that stage since the Industry 4.0 literature still lacks clear guidelines to help select vendors considering the various subjective factors involved and potential paybacks and returns on investment of some cutting-edge projects. Moreover, as pointed out in our practical contributions (Section 6.2), the implementation of vertical integration through the development of an ecosystem of technology providers working around Industry 4.0 solutions is a field that deserves more attention in the future. Prior studies have considered the development of ecosystems for testbeds and integrated solutions (e.g., Benitez et al., 2020; 2021), but they have not addressed details on the information system requirements and how this can be built around platforms and different companies working in an ecosystem. This can provide future avenues for the study of information systems in the Industry 4.0 field.

\section{Appendix}

Presentation: Thank you for accepting to be a part of our research on the adoption of information systems for vertical integration. We intend to understand the process of adoption these systems, from the emergence of their need to the decision to adopt them. We would like to point out that there are no right or wrong answers, and all the information provided is completely confidential and anonymous. Company data will be hidden under codenames.

i. Introduction

a. Ask about the company's Industry 4.0 view.

b. Ask about the interviewee activities in the company.

ii. Level of adoption of Information Systems (IS) for Vertical Integration (VI)

a. Does the company aim to gain visibility from vertical integration systems?

b. Explain your involvement with IS and actions aimed at VI of systems in the company.

c. What are the IS adopted by your company? (e.g., ERP, PLM, MES, PLM, etc.) d. What challenges does the company face in VI?

iii. Adoption strategies for Information Systems (IS) for Vertical Integration (VI)

a. Which IS have you had experience in adopting?

b. What was your role in this adoption?

c. Considering the IS you've had experience with (e.g., participated in adopting an MES in the company), explain how the demand for this system came about.

d. Explain the selection process for this new IS within the company, considering the diverse range of options on the market.

e. Explain the process to make the final decision to adopt that information system.

iv. Impact of Technology-Organization-Environment structure framework (TOE) factors in the adoption of Information Systems (IS) for Vertical Integration (VI)

a. What technological factors (relative advantage, uncertainty, compatibility, complexity, connectivity, expansion) do you think may impact the adoption of information systems in the context of I4.0 in your company? Why?

b. What organizational factors (company size, top management support, innovation capacity, culture, IT change) do you think might affect the adoption of information systems in the context of I4.0 in your company? Why?

c. What environmental factors (competitive pressure, industry, market scope, partnerships with suppliers) do you think may affect your company's adoption of information systems in the context of I4.0? Why?

Acknowledgements The authors thank the Brazilian National Council for Scientific and Technological Development $(\mathrm{CNPq}-$ Conselho Nacional de Desenvolvimento Científico e Tecnológico) (CNPq PQ2, and CNPq DAI), and the Research Coordination of the Brazilian Ministry of Education (CAPES PROEX) for the financial support received to conduct this research.

\section{Declarations}

Conflict of Interest The authors have no competing interests to declare that are relevant to the content of this article.

\section{References}

Alam, M., \& Khan, I. R. (2020). Business 4.0-A New Revolution. November. https://doi.org/10.6084/m9.figshare.14369636

Ali, O., Shrestha, A., Ghasemaghaei, M., \& Beydoun, G. (2021). Assessment of complexity in cloud computing adoption: a case 
study of local governments in Australia. Information Systems Frontiers. https://doi.org/10.1007/s10796-021-10108-w

Alshamaila, Y., Papagiannidis, S., \& Li, F. (2013). Cloud computing adoption by SMEs in the north east of England: A multi-perspective framework. Journal of Enterprise Information Management, 26(3), 250-275. https://doi.org/10.1108/17410391311325225

Antonio, G. D., Macheda, L., Bedolla, J. S., \& Chiabert, P. (2017). PLM-MES Integration to Support Industry 4. 0. 1, 129-137. https://doi.org/10.1007/978-3-319-72905-3

Ayala, N. F., Paslauski, C. A., Ghezzi, A., \& Frank, A. G. (2017). Knowledge sharing dynamics in service suppliers' involvement for servitization of manufacturing companies. International Journal of Production Economics, 193(August), 538-553. https://doi.org/ 10.1016/j.ijpe.2017.08.019

Bellini, P., Cenni, D., Mitolo, N., Nesi, P., Pantaleo, G., \& Soderi, M. (2021). High level control of chemical plant by industry 4.0 solutions. Journal of Industrial Information Integration, 100276. https://doi.org/10.1016/j.jii.2021.100276

Benitez, G. B., Ayala, N. F., \& Frank, A. G. (2020). Industry 4.0 innovation ecosystems: An evolutionary perspective on value cocreation. International Journal of Production Economics, 228(July 2019). https://doi.org/10.1016/j.ijpe.2020.107735

Benitez, G. B., Ferreira-Lima, M., Ayala, N. F., \& Frank, A. G. (2021). Industry 4.0 technology provision: the moderating role of supply chain partners to support technology providers. Supply Chain Management, November 2020. https://doi.org/10.1108/ SCM-07-2020-0304

Bose, R., \& Luo, X. (2011). Integrative framework for assessing firms' potential to undertake Green IT initiatives via virtualization - A theoretical perspective. Journal of Strategic Information Systems, 20(1), 38-54. https://doi.org/10.1016/j.jsis.2011.01.003

Branger, J., \& Pang, Z. (2015). From automated home to sustainable, healthy and manufacturing home: a new story enabled by the Internet-of-Things and Industry 4.0. Journal of Management Analytics, 2(4), 314-332. https://doi.org/10.1080/23270012.2015. 1115379

Brunelli, J., Lukic, V., Milon, T., \& Tantardini, M. (2017). Five lessons from the frontlines of industry 4.0. The Boston Consulting Group, November, 1-14. https://www.bcg.com/publications/2017/indus try-4.0-lean-manufacturing-five-lessons-frontlines.aspx. Accessed in July 2020

CNI, N. C. of I. (2016). Industry 4.0: a new challenge for Brazilian industry. CNI Indicators, April, 13. https://static-cms-si.s3.amazo naws.com/media/filer_public/13/e7/13e7e7bd-9b1d-4c16-809999b6d844d04e/special_survey_industry_40.pdf. Accessed in July 2020.

Cortimiglia, M. N., Ghezzi, A., \& Frank, A. G. (2016). Business model innovation and strategy making nexus: Evidence from a crossindustry mixed-methods study. $R$ and D Management, 46(3), 414-432. https://doi.org/10.1111/radm.12113

Dalenogare, L. S., Benitez, G. B., Ayala, N. F., \& Frank, A. G. (2018). The expected contribution of Industry 4.0 technologies for industrial performance. International Journal of Production Economics, 204(December 2017), 383-394. https://doi.org/10.1016/j.ijpe. 2018.08.019

Eisenhardt, K. M., \& Graebner, M. E. (2007). Theory building from cases: Opportunities and challenges. Academy of Management Journal, 50(1), 25-32. https://doi.org/10.5465/AMJ.2007.24160 888

El-Haddadeh, R. (2020). Digital innovation dynamics influence on organisational adoption: the case of cloud computing services. Information Systems Frontiers, 22(4), 985-999. https://doi.org/ 10.1007/s10796-019-09912-2

Fernandez-Viagas, V., \& Framinan, J. M. (2021). Exploring the benefits of scheduling with advanced and real-time information integration in Industry 4.0: A computational study. Journal of Industrial
Information Integration, 100281. https://doi.org/10.1016/j.jii. 2021.100281

Frank, A. G., Dalenogare, L. S., \& Ayala, N. F. (2019). Industry 4.0 technologies: Implementation patterns in manufacturing companies. International Journal of Production Economics, 210 (September 2018), 15-26. https://doi.org/10.1016/j.ijpe.2019.01.004

Ghobakhloo, M., \& Ching, N. T. (2019). Adoption of digital technologies of smart manufacturing in SMEs. Journal of Industrial Information Integration, 16. https://doi.org/10.1016/j.jii.2019.100107

Haleem, A., \& Javaid, M. (2019). Additive manufacturing applications in industry 4.0: a review. Journal of Industrial Integration and Management, 04(04), 1930001. https://doi.org/10.1142/s2424 862219300011

Hoyer, C., Gunawan, I., \& Reaiche, C. H. (2020). The implementation of industry 4.0-a systematic literature review of the key factors. Systems Research and Behavioral Science, 37(4), 557-578. https://doi.org/10.1002/sres.2701

Iaksch, J., Fernandes, E., \& Borsato, M. (2021). Digitalization and big data in smart farming-a review. Journal of Management Analytics, 8(2), 333-349. https://doi.org/10.1080/23270012.2021.1897957

ISA (2020). ISA - International Society of Automation. https://www. isa.org. Accessed in March 2021.

Ismail, A., \& Kastner, W. (2016). Vertical integration in industrial enterprises and distributed middleware. International Journal of Internet Protocol Technology, 9(2-3), 79-89. https://doi.org/10. 1504/IJIPT.2016.079547

Jain, V. K., \& Bhattacharyya, B. (2012). Advanced manufacturing processes. Journal of Manufacturing Technology Research, 4(1-2)

Jain, R., Chandrasekaran, A., Elias, G., \& Cloutier, R. (2008). Exploring the impact of systems architecture and systems requirements on systems integration complexity. IEEE Systems Journal, 2(2), 209-223.

Janssen, M., Weerakkody, V., Ismagilova, E., Sivarajah, U., \& Irani, Z. (2020). A framework for analysing blockchain technology adoption: Integrating institutional, market and technical factors. International Journal of Information Management, 50(April 2019), 302-309. https://doi.org/10.1016/j.ijinfomgt.2019.08.012

Javidroozi, V., Shah, H., \& Feldman, G. (2020). A framework for addressing the challenges of business process change during enterprise systems integration. Business Process Management Journal, 26(2), 463-488. https://doi.org/10.1108/BPMJ-03-2019-0128

Jeschke, S., Brecher, C., Meisen, T., Özdemir, D., \& Eschert, T. (2017). Industrial internet of things and cyber manufacturing systems. In Industrial internet of things (pp. 3-19). Springer.

Junior, C. H., Oliveira, T., \& Yanaze, M. (2019). The adoption stages (Evaluation, Adoption, and Routinisation) of ERP systems with business analytics functionality in the context of farms. Computers and Electronics in Agriculture, 156(January 2018), 334-348. https://doi.org/10.1016/j.compag.2018.11.028

Kagermann, H. (2013). Recommendations for implementing the strategic initiative INDUSTRIE 4.0. Acatech, April, 4-7

Kahle, J. H., Marcon, Ã., Ghezzi, A., \& Frank, A. G. (2020). Smart products value creation in SMEs innovation ecosystems. Technological Forecasting and Social Change, 156(November 2019), 120024. https://doi.org/10.1016/j.techfore.2020.120024

Khan, I. H., \& Javaid, M. (2021). Role of Internet of Things (IoT) in adoption of industry 4.0. Journal of Industrial Integration and Management, 6(2), 2150006. https://doi.org/10.1142/s242486222 1500068

Kusiak, A. (2018). Smart manufacturing. International Journal of Production Research, 56(1-2), 508-517. https://doi.org/10.1080/ 00207543.2017 .1351644

Li, L. (2018). China's manufacturing locus in 2025: with a comparison of "Made-in-China 2025" and "Industry 4.0." Technological Forecasting \& Social Change, 135(February 2017), 66-74. https://doi. org/10.1016/j.techfore.2017.05.028 
Liggesmeyer, P. (2014). Industry 4.0. Informatik-Spektrum, 37(4), 284-285. https://doi.org/10.1007/s00287-014-0809-1

Lin, B., Wu, W., \& Song, M. (2019). Industry 4.0: Driving factors and impacts on firm's performance: An empirical study on China's manufacturing industry. Annals of Operations Research, 1-21. https://doi.org/10.1007/s10479-019-03433-6

Liu, Z., \& Xie, K. (2020). A paradigm of safety management in Industry 4.0, 632-645. https://doi.org/10.1002/sres.2706

Longo, F., Nicoletti, E., \& Padovano, A. (2017). Smart operators in industry 4.0: a human-centered approach to enhance operators' capabilities and competencies within. Computers \& Industrial Engineering. https://doi.org/10.1016/j.cie.2017.09.016

Lu, Y. (2017). Industry 4.0: A survey on technologies, applications and open research issues. Journal of Industrial Information Integration, 6, 1-10. https://doi.org/10.1016/j.jii.2017.04.005

Maduku, D. K., Mpinganjira, M., \& Duh, H. (2016). Understanding mobile marketing adoption intention by South African SMEs: A multi-perspective framework. International Journal of Information Management, 36(5), 711-723. https://doi.org/10.1016/j. ijinfomgt.2016.04.018

Marcon, A., \& Ribeiro, J. L. D. (2021). How do startups manage external resources in innovation ecosystems? a resource perspective of startups' lifecycle. Technological Forecasting \& Social Change, 171(June), 120965. https://doi.org/10.1016/j. techfore.2021.120965

Marcon, Ã., Soliman, M., Gerstlberger, W., \& Frank, A. G. (2021). Sociotechnical factors and Industry 4.0: an integrative perspective for the adoption of smart manufacturing technologies. Journal of Manufacturing Technology Management, in press. https:// doi.org/10.1108/JMTM-01-2021-0017

Margherita, E. G., \& Braccini, A. M. (2020). Industry 4.0 technologies in flexible manufacturing for sustainable organizational value: reflections from a multiple case study of Italian manufacturers. Information Systems Frontiers. https://doi.org/10.1007/ s10796-020-10047-y

Masood, T., \& Egger, J. (2020). Adopting augmented reality in the age of industrial digitalisation. Computers in Industry, 115, 103112. https://doi.org/10.1016/j.compind.2019.07.002

Matyoqubov, M., Saidov, A., Kazakov, O., \& Rustamova, O. (2020). Enterprise systems data integration. 2020 International Conference on Information Science and Communications Technologies, ICISCT 2020, 2020-2022. https://doi.org/10.1109/ICISC T50599.2020.9351423

Meindl, B., Ayala, N. F., Mendonça, J., \& Frank, A. G. (2021). The four smarts of Industry 4.0: Evolution of ten years of research and future perspectives. Technological Forecasting and Social Change, 168(November 2020). https://doi.org/10.1016/j.techf ore.2021.120784

Nimawat, D., \& Gidwani, B. D. (2020). Prioritization of important factors towards the status of industry 4.0 implementation utilizing AHP and ANP techniques. Benchmarking: An International Journal. https://doi.org/10.1108/BIJ-07-2020-0346

Oliveira, T., Martins, R., Sarker, S., Thomas, M., \& Popovič, A. (2019). Understanding SaaS adoption: The moderating impact of the environment context. International Journal of Information Management, 49(June 2018), 1-12. https://doi.org/10. 1016/j.ijinfomgt.2019.02.009

Pereira, R. M., Szejka, A. L., \& Canciglieri, O. (2020). A Discussion on Current Issues for Semantic Interoperability in an Integrated Manufacturing System, 514-523. https://doi.org/10.3233/ ATDE200112

Pérez-Lara, M., Saucedo-Martínez, J. A., Marmolejo-Saucedo, J. A., Salais-Fierro, T. E., \& Vasant, P. (2018). Vertical and horizontal integration systems in Industry 4.0. Wireless Networks, 2. https://doi.org/10.1007/s11276-018-1873-2
Peruzzini, M., \& Stjepandić, J. (2017). Editorial to the special issue "Enterprise modelling and system integration for smart manufacturing. Journal of Industrial Information Integration, 7, 1-3. https://doi.org/10.1016/j.jii.2017.05.001

Peruzzini, M., \& Stjepandić, J. (2017). Editorial to the special issue information integration for innovative design and smart manufacturing. Journal of Industrial Integration and Management, 02(04), 1702003. https://doi.org/10.1142/s2424862217020031

Peruzzini, M., Gregori, F., Luzi, A., Mengarelli, M., \& Germani, M. (2017). A social life cycle assessment methodology for smart manufacturing: The case of study of a kitchen sink. Journal of Industrial Information Integration, 7, 24-32. https://doi.org/10. 1016/j.jii.2017.04.001

Qian, Y., Fang, Y., \& Gonzalez, J. J. (2012). Managing information security risks during new technology adoption. Computers and Security, 31(8), 859-869. https://doi.org/10.1016/j.cose.2012.09.001

Rogers, E. M. (2003). Diffusion of innovations, 5th ed. Free Press. https://doi.org/10.4324/9780203710753-35

Rogers, E. M., Singhal, A., \& Quinlan, M. M. (2019). Diffusion of innovations. In An Integrated Approach to Communication Theory and Research, Third Edition (5th ed., pp. 415-433). https://doi. org/10.4324/9780203710753-35

Romero, D., Stahre, J., \& Taisch, M. (2020). The operator 4.0: Towards socially sustainable factories of the future. Computers and Industrial Engineering, 139, 106128. https://doi.org/10.1016/j.cie.2019. 106128

Rossit, D. A., Tohmé, F., \& Frutos, M. (2019). A data-driven scheduling approach to smart manufacturing. Journal of Industrial Information Integration, 15(December 2018), 69-79. https://doi.org/ 10.1016/j.jii.2019.04.003

Saghiri, S., \& Wilding, R. (2021). On the effectiveness of supplier development programs: The role of supply-side moderators. Technovation, 103(January), 102234. https://doi.org/10.1016/j.techn ovation.2021.102234

Salam, M. A. (2019). Analyzing manufacturing strategies and Industry 4.0 supplier performance relationships from a resource-based perspective. Benchmarking, 28(5), 1697-1716. https://doi.org/10. 1108/BIJ-12-2018-0428

Schlechtendahl, J., Keinert, M., Kretschmer, F., Lechler, A., \& Verl, A. (2014). Making existing production systems Industry 4.0-ready: Holistic approach to the integration of existing production systems in Industry 4.0 environments. Production Engineering, 9(1), 143-148. https://doi.org/10.1007/s11740-014-0586-3

Schuh, G., Anderl, R., Dumitrescu, R., Krüger, A., \& Hompel, M. (2020a). Industrie 4.0 maturity index. Managing the Digital Transformation of Companies - UPDATE 2020 - (acatech STUDY)

Schuh, G., Anderl, R., Dumitrescu, R., Krüger, A., ten Hompel, M. (Eds.) (2020b) Using the Industrie 4.0 Maturity Index in Industry. Current challenges, case studies and trends (acatech COOPERATION), Munich. www.acatech.de. Accessed in March 2020.

Senyo, P. K., Effah, J., \& Addae, E. (2016). Preliminary insight into cloud computing adoption in a developing country. Journal of Enterprise Information Management, 29(4), 505-524. https://doi. org/10.1108/JEIM-09-2014-0094

Snyder, S., Meek, D., Lehtonen, T., \& Kiradjiev, P. (2020). Smart manufacturing. Ai technologies, intelligent insights. Expert Insights, IBM Institute for Business Value, $N Y$. https://www.ibm.com/downl oads/cas/ZLKE8R2X. Accessed in March 2021.

Sony, M., \& Naik, S. (2020). Critical factors for the successful implementation of Industry 4.0: a review and future research direction. Production Planning \& Control, 31(10), 799-815. https://doi.org/ 10.1080/09537287.2019.1691278

Sony, M., \& Naik, S. S. (2019). Ten lessons for managers while implementing Industry 4.0. IEEE Engineering Management Review, $47(2), 45-52$. 
Tamas, L., Murar, M., \& Tamas, L. (2019). Smart CPS: vertical integration overview and user story with a cobot Smart CPS: vertical integration overview and user story with a cobot. International Journal of Computer Integrated Manufacturing, 32(4-5), 504521. https://doi.org/10.1080/0951192X.2018.1535196

Thong, J. Y. L. (1999). An integrated model of information systems adoption in small businesses. Journal of Management Information Systems, 15(4), 187-214. https://doi.org/10.1080/07421222. 1999.11518227

Tornatzky, L. G., \& Fleischer, M. (1990). The Process of Technological Innovation. Lexington Books

Uysal, M. P., \& Mergen, A. E. (2021). Smart manufacturing in intelligent digital mesh: Integration of enterprise architecture and software product line engineering. Journal of Industrial Information Integration, 22(February), 100202. https://doi.org/10.1016/j.jii. 2021.100202

Voss, C., Tsikriktsis, N., \& Frohlich, M. (2002). Case research in operations management. International Journal of Operations and Production Management, 22(2), https://doi.org/10.1108/ 01443570210414329

Wang, S., Wan, J., Li, D., \& Zhang, C. (2016). Implementing Smart Factory of Industrie 4.0: An Outlook. International Journal of Distributed Sensor Networks, 2016. https://doi.org/10.1155/2016/ 3159805

Wei, J., Lowry, P. B., \& Seedorf, S. (2015). The assimilation of RFID technology by Chinese companies: A technology diffusion perspective. Information and Management, 52(6), 628-642. https:// doi.org/10.1016/j.im.2015.05.001

Xu, L., Da, Xu, E. L., \& Li, L. (2018). Industry 4.0: State of the art and future trends. International Journal of Production Research, 56(8), 2941-2962. https://doi.org/10.1080/00207543.2018.1444806

Yeo, B., \& Grant, D. (2018). Predicting service industry performance using decision tree analysis. International Journal of Information
Management, 38(1), 288-300. https://doi.org/10.1016/j.ijinfomgt. 2017.10.002

Yin, R. K. (2009). Case study research: Design and methods (Vol. 5). Sage.

Publisher's Note Springer Nature remains neutral with regard to jurisdictional claims in published maps and institutional affiliations.

Verônica Maurer Tabim, M.S. is a PhD candidate in Industrial Engineering at the Federal University of Rio Grande do Sul (UFRGS) - Brazil, and a researcher of the Organizational Engineering Group (NEO Núcleo de Engenharia Organizacional) from the Department of Industrial Engineering at UFRGS.

Néstor Fabián Ayala, Ph.D. is Associate Professor of Service Engineering at the Federal University of Rio Grande do Sul (UFRGS) - Brazil, and the co-director of the Organizational Engineering Group (NEO - Núcleo de Engenharia Organizacional) also at UFRGS. He has been a visiting professor at the Institute Polytechnic of Grenoble (Grenoble INP), France. His main research interests include strategic management and operations management with focus on digitalization, Industry 4.0 and servitization of manufacturing.

Alejandro G. Frank, Ph.D. is an Associate Professor of Industrial Organization at the Department of Industrial Engineering and the director of the Organizational Engineering Group (NEO - Núcleo de Engenharia Organizacional) both at the Federal University of Rio Grande do Sul, Brazil. He has been a research affiliate at the Massachusetts Institute of Technology (USA), and a visiting researcher at Politecnico di Milano (Italy). His research is devoted to the interface between operations and technology management, with emphasis on digital transformation, Industry 4.0, and new business models in manufacturing firms. 